artigo $]$

[ PATRICIA REINHEIMER ]

Professora de Antropologia do Departamento de Ciências Sociais da UFRJ.

Graduação em licenciatura em Artes, com mestrado e doutorado em Antropologia Social pelo PPGAS/MN.

E-mail: patriciareinheimer2007@gmail.com

\title{
Olly Reinheimer: a invenção de uma moda brasileira através da dialética entre natureza e cultura'
}

\author{
Olly Reinheimer: Brazilian fashion \\ invention through the dialetics between \\ nature and culture
}

\begin{abstract}
[resumo] Diversas mudanças na segunda metade do século XX influenciaram a transformação de valores e contribuíram para a reinvenção de identidades e estilos de vida e o surgimento de novas classificações sociais. No Brasil, a indumentária representada aqui pelo trabalho da artista Olly Reinheimer foi essencial nesse processo. Jovens e mulheres apareceram principalmente a partir da década de 1960 como categorias relevantes em termos de consumo e mercado de trabalho. Ipanema e Copacabana foram transformadas em metonímias da modernidade cultural cantada pela Bossa Nova, com o apoio das instituições de arte moderna que surgiam no Brasil. Os discursos sobre as roupas de Olly e também sobre decoração e o desenho gráfico mostraram como a forma de se relacionar com o espaço - em suas diversas acepções - parecia ser um dos eixos dessa transformação.
\end{abstract}

\section{palavras-chave}

\section{arte; moda; Ipanema.}

[abstract] ISeveral changes in the second half of the twentieth century influenced the transformation of values and contributed to the reinvention of identities and lifestyles. In Brazil, clothes represented here by the work of Olly Reinheimer was essential in this process. Young people and women appear mainly in the 1960s as relevant categories in terms of consumption and the labor market. Ipanema and Copacabana were transformed into a metonymy of cultural modernity sung through the Bossa Nova songs, with the support of modern art institutions that arose in Brazil. The discourses over Olly's clothes and also about decoration and graphic design show how the relationship with space - in its many meanings - seemed to be one of the keynotes of this transformation.

[keywords] art; fashion; Ipanema. 


\section{Introdução: Ipanema era só felicidade}

Benedict Anderson argumenta sobre a importância da visualidade na construção das nações modernas. No início do Renascimento, séculos XV e XVI, o mundo representava a realidade essencialmente através de um imaginário visual e sonoro fundado no presente. A história do mundo era sempre representada com personagens que se vestiam "à moda" da época do pintor que construía a representação e não da época em que viveram os personagens. A concepção histórica não era baseada em uma relação linear de causas e efeitos nem em separações radicais entre passado e presente.

Nessa perspectiva visual, os meios técnicos que permitiram a circulação de jornais e romances foram fundamentais para "re-presentar" a nação cuja imaginação estava se formando. É da onisciência do leitor acerca do que fazem os personagens e a ciência de que todos pertencem a uma mesma "sociedade", cujas ações estão em sincronia através de um único calendário e sistema de marcação do tempo, que surgiu a ideia de um pertencimento a um sistema social imaginário de pessoas que não se conheciam: "a ideia de um organismo sociológico atravessado cronologicamente por um tempo vazio e homogêneo é uma analogia exata da ideia de nação, que também é concebida como uma comunidade sólida percorrendo constantemente a história" (ANDERSON, 1983, p. 56).

A temporalidade dos periódicos diários foi fundamental para a invenção de novas formas de pertencimento. A obsolescência mesma dessas publicações contribuiu para a percepção da simultaneidade: todos liam a mesma notícia, no mesmo dia. No dia seguinte, novas notícias e assim por diante, mantendo o fluxo de informações que parecia tornar todos parte de uma mesma comunidade de imaginação, cotidianamente (o tal plebiscito diário?). 0 desenvolvimento da imprensa como mercadoria foi assim chave para a criação de ideias radicalmente novas sobre a simultaneidade e a identidade.

Na segunda metade do século XX a imprensa também teve grande influência na transformação dos valores, mas foram outras as mudanças que contribuíram para reinventar as identidades das quais, também no Brasil, a indumentária fez parte. A partir da década de 1950, a entrada de mulheres casadas no mercado de trabalho e a expansão da educação superior transformaram as mulheres em geral, até o fim da década de 1980, em uma força política como até então não se vira.

Os jovens também apareceram como grupo socialmente relevante. Segundo Hobsbawm, "a partir do fim da década de 1960, houve uma tendência a baixar a idade eleitoral para dezoito anos - por exemplo, nos EUA, Grã-Bretanha, Alemanha e França - e também algum sinal de redução da idade de consentimento para o intercurso sexual (heterossexual)" (2005, p. 319). Os jovens também tinham poder de compra, por serem os pais adultos de uma geração que tinha vivido os tempos de escassez. Esse novo grupo também estava em vantagens em relação aos grupos etários mais conservadores em um mundo de rápidas mudanças tecnológicas por serem menos resistentes a adaptações.

A descoberta desse mercado jovem, em meados de 1950, revolucionou o comércio da música popular e o mercado de massa da indústria da moda na Europa. As mulheres que trabalhavam em escritórios eram mais suscetiveis às seduções das propagandas de novos produtos que os homens. No entanto, na moda brasileira ainda predominava a importação de modelos europeus. Na música, João Gilberto, Tom Jobim e Vinicius de Moraes projetaram, pela primeira vez, o pais para o mundo, por meio da Bossa Nova. Esse grupo de músicos vivia no Rio de Janeiro, mais especificamente em Ipanema, centro de uma revolução na cultura e nos costumes.

Ruy Castro argumenta que, enquanto Copacabana era a vitrine da Bossa Nova, por ser nos bares daquele bairro que os músicos se apresentavam, era em Ipanema que moravam e estavam os bares onde se encontravam e faziam suas músicas. Nas décadas de 1950 e 1960, os jovens que frequentavam o Arpoador conviviam com 
intelectuais como Lúcio Cardoso, Rubem Braga e Paulo Mendes Campos e se misturavam com o pessoal da Bossa Nova.

Na década de 1950, o consumo de discos se ampliou com a invenção do LP. Mas foi nos anos 1970 que a fita cassete (K7), inventada em 1963, tornou a música facilmente reprodutivel e transportável em, cada vez menores, gravadores portáteis. 0 projetor de slides, transparências em $35 \mathrm{~mm}$, já existia no fim da década de 1930. No entanto, seu uso se popularizou a partir de 1961, quando a Kodak lançou o projetor de carrossel. Imagem e som podiam agora ser consumidas juntas, caseiramente. Assim, as formas de apreensão da criação artística na era da "reprodutibilidade técnica" se transformaram radicalmente. As impressões dos sentidos podiam se dar simultaneamente a partir de uma diversidade de formas - voz, impressão e som, em espaços públicos, ou em eventos privados: "a tecnologia encharcara de arte a vida diária privada e pública. Jamais fora tão difícil evitar a experiência estética" (HOBSBAWM, 2005, p. 502).

$\mathrm{Na}$ arte também ocorrera uma revolução de valores após o fim da Segunda Guerra. No Brasil, a abertura dos Museus de Arte Moderna se iniciou no Rio, em 1948, e se estendeu por São Paulo, Salvador e Belo Horizonte. A morte de Mário de Andrade, um dos principais idealizadores do Modernismo paulista, em 1945, abrira caminho para a discussão de novos cânones. Mario Pedrosa assumiu o papel de revisor desses valores, sobre os quais se apoiava o mundo artístico de então. Em 1960, após mais de dez anos de investimentos contra o Modernismo das décadas de 1920 e 1930, assumiu a direção do Museu de Arte de São Paulo e da VI Bienal de São Paulo.

0 que Pedrosa contribuíra para institucionalizar no Brasil era aquele "modernismo" que, desde fins do século XIX, legitimava na Europa a prática da criação artística não utilitária, justificando a reivindicação da liberdade total do artista. Seu cânone era a ruptura, a inovação (HEINICH, 1993; ZOLBERG, 2009), nas décadas de 1950 e 1960. 0 abstracionismo foi acionado como forma de rejeitar a cooptação dos artistas por parte dos ideais políticos nacionais, como tinha acontecido durante o periodo Vargas. Após a Segunda Guerra, no Brasil, nos EUA e na Europa, tendeu-se a associar a modernidade na arte ao não figurativo. Só no fim da década de 1960, o abstracionismo perdeu sua hegemonia, dando novamente espaço para a representação.

Esse era o pano de fundo tecnológico e artístico para o qual o trabalho de Olly Reinheimer com indumentária contribuiu ao levantar questões sobre a natureza e a cultura da América Latina e do Brasil na construção da subjetividade da artista e de outros agentes que pertenceram à sua rede de relações.

\section{Dia de luz, festa de sol e o macio azul do mar}

Olly se integrou ao ambiente artístico carioca, a partir de Ipanema, onde morava, na década de 1950. Estudou cerâmica com Margareth Spence, inicialmente, e em 1952 participou de sua primeira coletiva, o II Salão de Arte Moderna do Rio de Janeiro (SAM-RJ). Em 1953, ganhou o prêmio aquisição em cerâmica, no III SAM-RJ.

Entre 1951 e 1953 fundou, com Geny Marcondes, o Clube de Artes Infantil, com aulas aos sábados, das 13 às 17 horas. Em 1951 as aulas aconteceram na rua Nascimento e Silva, na garagem da casa de Geny; em 1952, no Colégio Brasileiro de Almeida; e, em 1953, na filial do Conservatório Brasileiro de Música, no antigo Posto 6. Olly ensinava cerâmica, Geny Marcondes, música e Maria Teresa Vieira, pintura e desenho. No entanto, poucos anos depois, uma intoxicação com as químicas da cerâmica fez Olly se voltar para outras atividades. Decidiu investir em diversos cursos de arte no MAM-RJ e, a partir de 1957, começou a usar os conhecimentos acumulados em tecidos.

Em seus manuscritos, Olly reclama da forma como seu professor Ivan Serpa tratava seus alunos. Mais do que falar das concepções didáticas do professor, a reclamação pareceu servir como contraponto à informação de que o pintor elogiou sua sensibilidade e encomendou um trabalho seu. Segundo Maria Inês de Almeida, Geny Marcondes foi fundamental na direção que Olly tomou rumo ao trabalho com roupas: 
Geny me chamou e disse: Maria Inês vem aqui conhecer uma amiga minha que pinta coisas lindíssimas. E eram lenços extraordinários, grandes, para usar no pescoço. Sempre que uso as pessoas ficam deslumbradas. E aí eu disse: eu vou comprar esse lenço, mas eu não quero um lenço, quero um vestido. Foi seu primeiro corte para vestido. No dia seguinte ela estava aqui com o tecido. Usava-se um vestido no estilo Ava Gardner. E eu fiz um vestido naquele estilo. Quando eu a conheci, ela ainda não tinha nenhuma vida pública. Então é capaz de ter sido em 1957, 1958 .

Em 1962, Olly foi ensinar pintura em tecidos na Galeria de Arte Contemporânea, do Instituto de Arte Contemporânea, em Lima, no Peru. Essa viagem, Olly fez junto com Arcangelo lanelli, que expunha em outra sala da mesma instituição. No ano seguinte, voltou a Lima para expor no The Art Center. Nessas viagens, visitou sítios arqueológicos e adquiriu peças de cerâmica e tecidos Paraca que serviram de influência em seu trabalho, principalmente na estilização dos pássaros e peixes aproveitados em tecelagens e xilogravuras aplicadas ao tecido (figura 1).

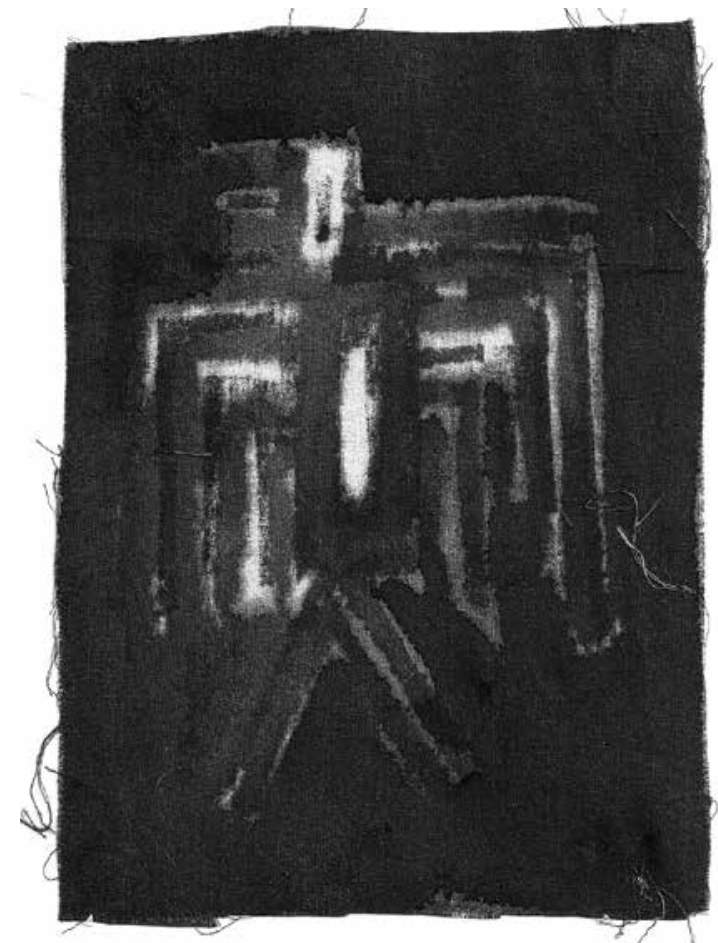

Figura 1: Amostra de estamparia. Referência Olly- PACA-0050-B do Arquivo Olly e Werner Reinheimer.

Em 1966, Olly expôs na Pinacoteca do Museu de Arte de São Paulo, MASP4. Foram 40 peças de inspiração pré-colombiana. A artista diz que a ideia inicial foi do diretor do museu de arqueologia local, em Lima. 0 próprio MASP tinha uma coleção de objetos pré-colombianos e, em 1978, a Fundação Cultural Ema Gordon Klabin inaugurou também com uma coleção desses objetos. Olly fez parte de sua formação na fábrica Klabin, no Rio de Janeiro. Provavelmente teve contato com essa família de imigrantes lituanos. No entanto, mais importante do que confirmar esses contatos, nesse caso, é saber que esse era um tema em voga naquele momento. Colecionar peças pré-colombianas constituía uma forma de distinção valorizada como parte de um acervo artístico e científico que procurava construir a totalidade latino-americana em oposição à europeia. É importante lembrar que, até a década de 1980, as discussões sobre nação e nacionalismo ainda estavam fundadas na ideia de homogeneidade e totalidades físicas e culturalmente delimitadas entre si. 


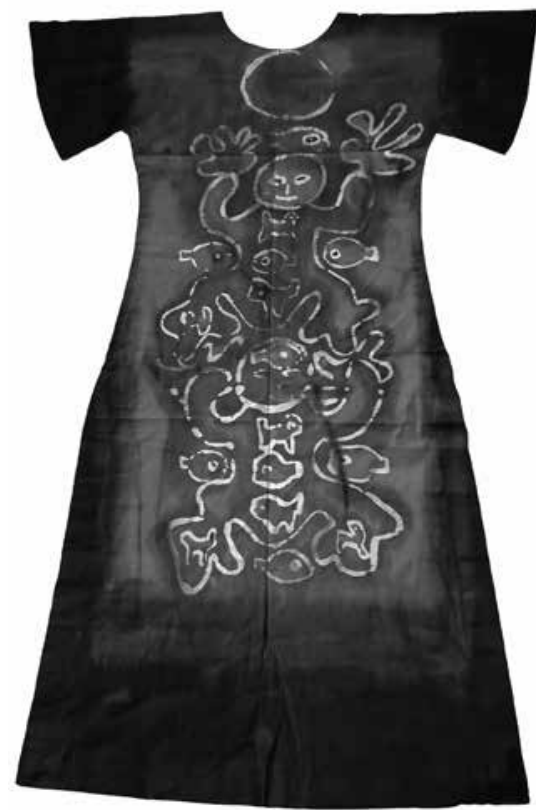

Figura 2: A pintura desse vestido lembra as referências Paraca. Referência Olly-PACT-24 do Arquivo Olly e Werner Reinheimer.

Desde 1956, a Fundação Bienal de São Paulo tentava apresentar peças de povos pré-colombianos. A primeira tentativa foi com a arquitetura mexicana pré-hispânica, mas só em 1963, na VII Bienal de Arte de São Paulo, é que uma mostra de peças do período pré-colombiano de diversos países americanos foi realizada. 0 resultado da mostra foi a posterior constituição do Museu de Arte e Arqueologia da Universidade de São Paulo, mais tarde renomeado Museu de Arqueologia e Etnologia - MAE (MAZIERO, 2015).

Em 1969, Olly apresentou, no MAM do Rio de Janeiro, uma coleção de roupas em um happening com fotografias de David Drew Zing; ambientação de Pedro Sayad; coordenação geral de Karl Bergmüller, da Bauhaus e da Escola de Desenho Industrial; joias de Pedro Correia de Araújo; música de Rogério Coimbra, com as manequins Lúcia Lemos, Maria Teresa, Patricia Niemeyer, Tania, Eunice Araújo e Márcia Rodrigues. Foram apresentados tecidos pintados e serigrafados que usavam como referência elementos naturais da fauna e da flora brasileiras e estampas inspiradas na pintura corporal e nas bonecas dos indios carajá $^{5}$ (figuras 3 e 4). A exposição inaugurada com música "eletrônica" teve a apresentação de modelos que desfilavam com movimentos estilizados sob a projeção de imagens diversas (infelizmente em nenhum lugar se mencionou que imagens foram mostradas).

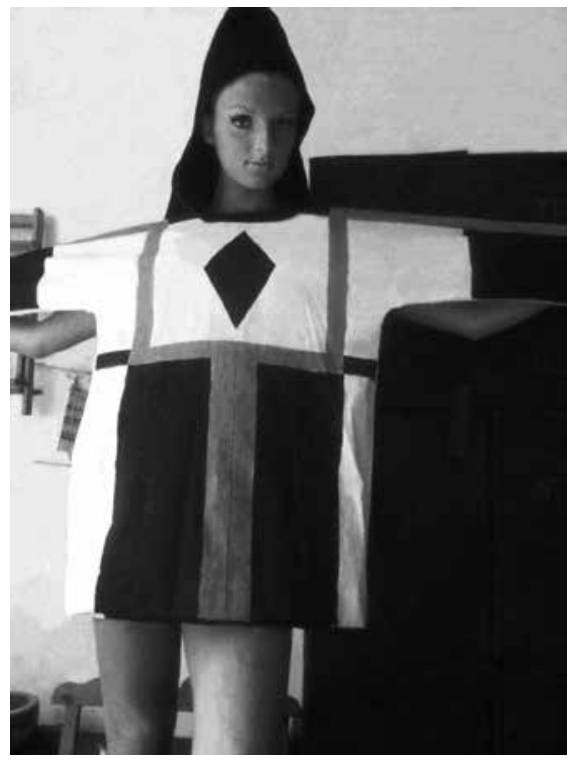


Comentaram a exposição Antonio Bento, Quirino Campofiorito e Frederico Morais, entre outros. 0 cartaz da exposição era um vestido curto com as letras MAM tomando todo o corpo do vestido, pintadas em preto, usando uma fonte sem serifa, como a logomarca da instituição à época ${ }^{7}$. No texto para a exposição, Marc Berkowitz falou em vestidos-objetos que no corpo das modelos se transformariam em esculturas (figura 5).

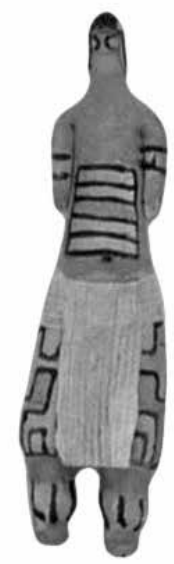

Figura 4: Licocó, boneca em cerâmica, carajá. Referência Olly-SI-046 do Arquivo Olly e Werner Reinheimer.

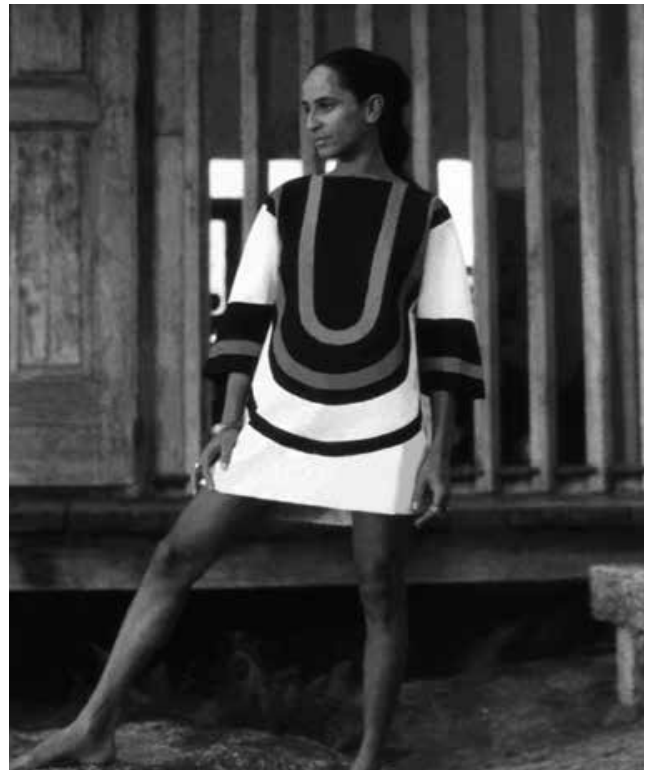

Figura 5: Maria Bethânia, fotografada por Mariza Alvarez de Lima, para Manchete, em sua casa desenhada pelo arquiteto Zanini Caldas. Referência Olly-SI-643 do Arquivo Olly e Werner Reinheimer.

Em entrevista sobre a exposição, Olly declara: "Eu sou brasileira, e o que me importa mais divulgar no estrangeiro são as cores, as formas e o espirito eminentemente brasileiro. Nesse ponto, meus vestidos inspirados nos bonecos dos índios carajá são os mais importantes desta mostra. Os que lembram flores e pássaros são representativos enquanto coisa tropical e agradam sempre, mas há outros países tropicais. Os carajá não: é Brasil puro"8. Trata-se de uma releitura das apropriações indígenas influenciadas pelo Romantismo, mas agora não se tratava mais de um índio abstrato, ainda que o grupo ganhasse representação a partir das escolhas de uma artista de ascendência europeia. No vernissage, um tecido branco foi usado para que as pessoas assinassem e comentassem a exposição. Ali se lê em vermelho: "Brèsil, je t'aime". 
Antonio Bento discorreu sobre a exposição falando de edições limitadas e "numeradas de seus vestidos, através do processo de serigrafia, como se usa na gravura". Tratava-se de todo um léxico artístico que incluia a forma de apresentação, a menção aos estilos e influências, e também questões como a limitação e o controle da quantidade. A inexistência de uma "moda brasileira" tornaria, segundo Bento, a experiência de Olly ainda mais "fecunda". Segundo o crítico, a artista

inspira-se em formas e ideogramas pré-colombianos e na pintura dos indios carajá. A artista faz verdadeiros assemblages, utilizando-se fibras, conchas, caramujos, seixos rolados e outras bossas que despertam comentários hostis ou intrigados dos profissionais da alta-costura"9.

Em um manuscrito, Olly argumentou que a exposição foi feita em pouco tempo e por isso cortou e costurou as roupas em tecido cru, desenhou a lápis o que deveria ser pintado e os amigos ajudaram a pintar os modelos ${ }^{10}$. Foram assim expostos "protótipos" de roupas que as pessoas usaram para encomendar no tamanho e tecidos desejados. Esses foram inclusive feitos com tintas não específicas que manchavam ${ }^{11}$. Isso a aproximava ainda mais de um incipiente campo artístico que, cada vez mais, insistia no atravessamento de fronteiras como forma de reivindicar autonomia, mas afastava-a de uma moda que trabalhava na época com coleções bianuais. A indumentária ganhava em valor ao afastar-se do mercado e seus ciclos, e a arte ganhava com mais uma artista que defendia a liberdade de expressão na escolha dos materiais e na forma de apresentar seu trabalho.

Um recorte de jornal do ano seguinte apresenta Duda Cavalcanti com uma roupa da linha carajá12 (figura 6). 0 filho da artista comentou o sucesso da coleção: "foi uma paixão, todo mundo queria uma roupa com pintura carajá. A casa vivia cheia depois dessa exposição"13.

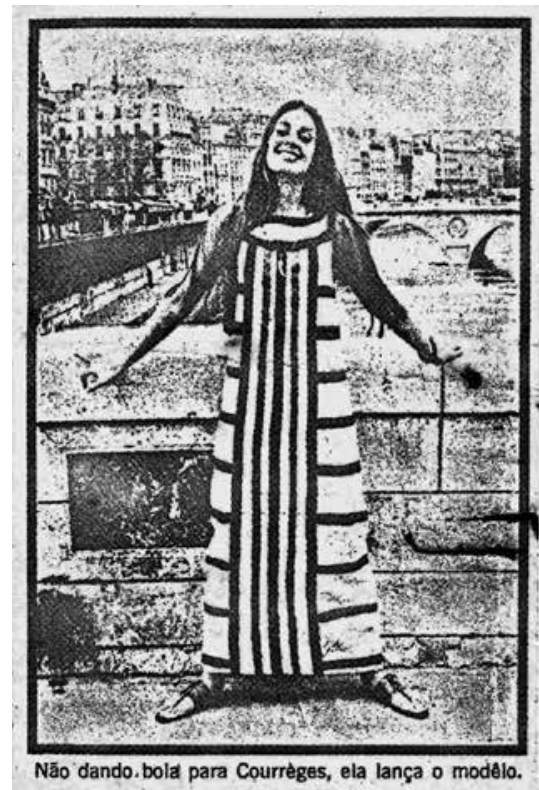

Figura 6: Duda Cavalcanti em Paris. Referência Olly- MROW-G-39 do Arquivo Olly e Werner Reinheimer.

Produzir nessa encruzilhada entre arte e moda não foi simples. Olly reclamou, por exemplo, da forma como sua exposição em uma galeria de São Paulo foi tratada. Segundo ela, outros artistas que lá expuseram puderam modificar livremente a galeria 
para expor seus trabalhos, enquanto a ela foi vetado o uso de pregos para pendurar suas coisas. Conta também que, quando mostrou sua pintura sobre tecido ao pintor Domenico Lazzarini, este recusou o rótulo de pintura, por não estar em uma tela com chassis. Conhecer algumas dificuldades vividas por ela contribui para percebermos como as convenções limitavam na época um campo que estava se construindo para assumir a ruptura como cânone, ou seja, como a cooperação em sua forma negativa (BECKER, 1982) influía nas transformações do mundo artístico da época.

As duas coleções descritas assumem mais explicitamente o discurso de uma identidade fundada na ideia de primitividade e ancestralidade. No entanto, a vinculação do trabalho de Olly com os elementos a partir dos quais se imaginar o Brasil - as cores, a luz, o mar, o céu, o horizonte e o pôr do sol - aparece nos tecidos cujo elemento principal é a cor e que, no discurso, são vinculados a manifestações populares, como o bumba-meu-boi, a fauna e a flora brasileiras (figura 7).

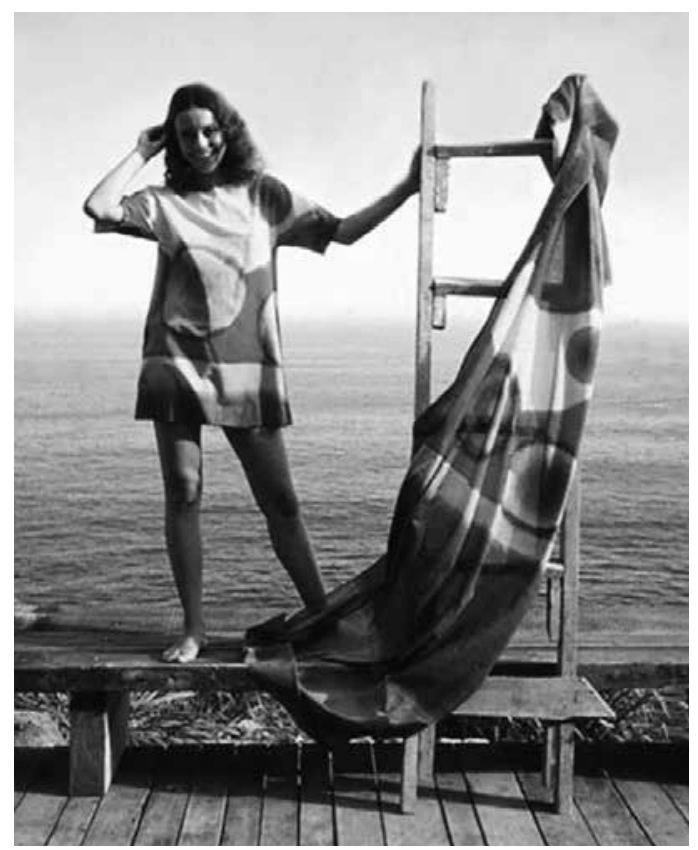

Figura 7: Referência Olly-DIA-009 do Arquivo Olly e Werner Reinheimer, s/d.

A natureza apareceu também como referência de sua última exposição "Origens: cores, formas, texturas", na galeria Candido Mendes, em Ipanema, em 1981. Nessa exposição, a natureza já não era nacionalizada. Pelo contrário, as peças foram apresentadas como tendo sido coletadas ao longo de sua vida e em espaços geográficos distintos por onde passou em suas viagens (figura 8). Por um lado, conquistado seu espaço no campo artístico, Olly parecia não precisar mais afirmar seu pertencimento nacional. Pelo contrário, afirmar uma formação universalista era dar subsídios ao reconhecimento que o campo Ihe outorgava. Por outro lado, a distância dos conflitos que trouxeram ela e sua familia para o Brasil, assim como o iminente fim da ditadura civil-militar também pode ter contribuído para a diminuição da necessidade de reforçar certo "patriotismo" como forma de desviar atenção de seu sotaque, suas raízes judaicas e as atuações políticas de seu marido ${ }^{14}$. 

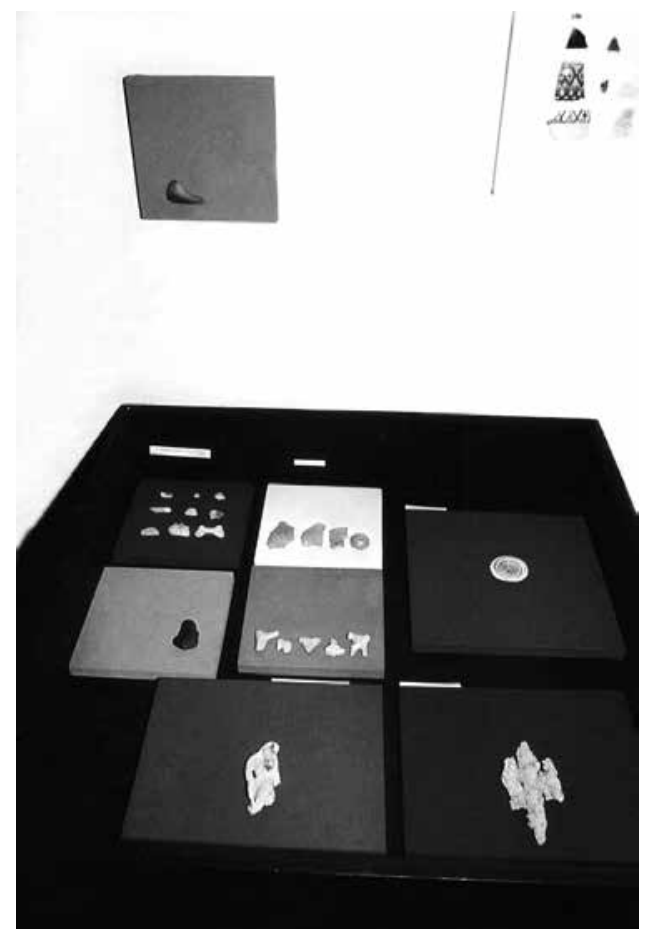

Figura 8: Última exposição organizada por Olly. Referência Olly-DIA-074 do Arquivo Olly e Werner Reinheimer, 1981.

\section{Distinção, identidade e ancestralidade como positivação do primitivo}

Em Ipanema, principalmente a partir da década de 1950 teve início a construção dos valores de uma contracultura cujo apogeu foi na década de 1960 e resistiu até 0 começo da abertura, no fim da década de 1970 (CASTRO, 1999).

0 livro de Ruy Castro (1999), Ela é carioca, pode ser lido como um resumo do processo de surgimento de uma nova mentalidade que teve Ipanema como palco e ao mesmo tempo personagem em crônicas, prosas, músicas, peças de teatro, filmes para cinema e programas para televisão. Nesse período, produziu-se certo folclore sobre o bairro, através do comportamento e valores de alguns de seus moradores. A Bossa Nova, principalmente, mas também o Cinema Novo foram os responsáveis por projetar Ipanema internacionalmente como espaço de experimentação dos costumes, tornando o bairro uma metonímia do Brasil ${ }^{15}$.

Em Ipanema, os valores das décadas de 1950 a 1970 se constituíram com base em uma mistura de grupos étnicos distintos, sem a predominância aparente de nenhum deles. Entretanto, ampliando os limites geográficos dessa transformação dos costumes, um grupo profissional aparece como um dos principais responsáveis pelas transformações nos valores a partir dos objetos que compunham a dimensão mais visivel daquela nova mentalidade, os designers - principalmente de móveis, joias, indumentária, interior e o design gráfico. Ainda que nem todos fossem classificados como designers, todos trabalhavam seguindo um projeto original, tendo a multiplicação limitada, ou não, de seus produtos como horizonte ideal de comercialização.

A nova linguagem gráfica que incluía capas de discos, livros e revistas (a revista Senhorfoi a mais paradigmática - de março de 1959 a janeiro de $\left.1964^{16}\right)$, mas também o uso dos asteriscos como substituição aos palavrões, que passaram a fazer parte da linguagem corrente, como mais uma forma de fugir às convenções morais de bom comportamento (CASTRO, 1999).

Caio Mourão, por exemplo, além de designer de joias internacionalmente reconhecido, integrou com Jaguar e Bea Feitler a editoria de arte da revista Senhor, chefiada por Carlos Scliar e Glauco Rodrigues. Essa revista foi uma das responsáveis pela reformulação da relação entre texto e imagem que iria resultar em novos padrões visuais na arte gráfica. Bea Feitler depois foi diretora de arte da Haaper's Bazaar e influência declarada (no documentário $A$ vida através das lentes) da fotógrafa Annie Leibowitz. Juarez Machado desenhou joias para Caio Mourão e também vitrines de lojas, selos, roupas, rótulos de embalagens e, na década de 1970, ficou conhecido por um quadro de mímica que fazia na televisão. Márcio Mattar, ex-aluno de Caio Mourão, tornou-se designer de joias. 
Só em Ipanema, pode-se enumerar uma série de lojas de móveis que transformaram o ambiente cotidiano dos cariocas. Em 1955, Sérgio Rodrigues (1927-2014) inaugurou a Oca, na praça General Osório. Essa loja servia de sala de espera para seu vizinho, o Teatro de Bolso, de Silveira Sampaio (1914-1964). Nela, Sérgio Rodrigues produziu a "poltrona mole", pela qual foi premiado, em 1957. Nos anos 40, o português Joaquim Tenreiro, que chegara ao Rio em 1928, abriu uma loja de móveis em Copacabana e transformou-a em galeria de arte, apresentando nomes como Volpi, Goeldi, Scliar, Dacosta, Serpa e outros. Por sugestão de Sérgio Rodrigues, em 1959, mudou a loja para Ipanema. Na mesma região, outras lojas de design de móveis eram a loja de Emeric Macier, a de Christian Roule e a Meia-pataca, também de Sérgio Rodrigues, versão mais popular da Oca.

Norman Westwater, que chegou ao Brasil em 1952 fugindo de uma Europa que vivia as dificuldades do pós-guerra, fundou em 1954, na mesma praça, a Mobília Contemporânea. Nessa loja, ficava a Galeria Contemporânea, que sediou a primeira exposição de Olly, em 1958. Ali, ele apresentava as mobílias modulares que desenhava junto com Michel Arnauld. Em 1957, desenhou os enfeites natalinos para as ruas do centro da cidade e, em 1958, os enfeites de carnaval. Fez diversos trabalhos para teatro e cinema, que incluíram Orfeu Negro e Hello Dolly, com Bibi Ferreira. Deu aulas de design de palco na Universidade da Bahia e, em 1964, foi um dos membros fundadores da ABDI, Associação Brasileira de Desenho Industrial e professor da Esdi, Escola Superior de Desenho Industrial, entre 1964 e 1965.

Pelas revistas de decoração, podemos ter uma ideia das transformações que esses designers suscitaram por meio de uma ênfase na fauna e na flora tropical e/ou brasileira, assim como pela revisão do Romantismo, para incluir nele não mais necessariamente a ideia de uma identidade nacional brasileira, mas a ideia de uma modernidade aliada ao primitivismo. 0 termo rústico apareceu nesse período como uma alusão a essa mistura, aparentemente contraditória se levarmos em conta que, na década de 1950, alguns cientistas sociais ainda estavam contrapondo o "homem da cidade" ao "homem rústico".

Em 1966, o primeiro número da revista Interior e Decoração apresentava no editorial seu objetivo: "despertar e desenvolver o gosto, aprimorar a habilidade de escolher e aumentar a firmeza de decisões do leitor". Rejeitando a noção de valor econômico, investia na estética como critério de distinção fundado na interioridade:

\footnotetext{
Não é dirigida a determinado nível de orçamento, pois, basicamente, o chamado bom gosto tem pouco a ver com os preços caros. $E$ sim com a faculdade de reconhecer as diferenças entre as formas belas e formas vulgares, entre as combinações harmoniosas ou não de cores e entre um agrupamento apropriado ou não dos elementos de decoração ${ }^{17}$.
}

Nas fotos, percebe-se que a principal referência para a decoração ainda era a Europa. Tanto as imagens como a grafia do português apresentavam anglicismos e francesismos: "no living a "lâmpada a óleo da época de Carlos X", completava o ambiente francês, exposto no Design Center de New York, com peças do período Luís XIV, agradável para passar o week-end". Os ambientes apresentados ainda eram de museus e filmes que remetiam à Europa e aos EUA. Assim, o trabalho de Cecil Beaton em My fair lady era apresentado como um exemplo de ambiente romântico, na reprodução de um artigo publicado pela American Caxon Institute. Era ainda um designer americano, George Nelson, que era oferecido como exemplo na produção de interiores modernos, pelas linhas retas e aproveitamento de espaço.

0 apartamento de Olly foi apresentado ali como exemplo de decoração de interior. Destoando dos outros ambientes, o apartamento era apontado como modelo de 
"simplicidade e bom gosto". A sala, dois quartos e o corredor foram mostrados em dez fotos distribuídas em cinco páginas. As coisas expostas remetiam à ideia de origem e primitividade: o moedor de café antigo, o pilão de madeira carcomida pelo tempo, um ferro provavelmente do século XIX, peças pré-colombianas e plantas compunham os diversos ambientes apresentados na matéria. Um quadro cusquenho, por exemplo, era definido como "arte cusquenha primitiva". "Uma arca e uma mesa mineira" remetiam sem mencionar, ao mesmo tempo, ao Modernismo brasileiro de Mário de Andrade e Tarsila do Amaral e ao primitivismo brasileiro do qual esse Modernismo se nutriu. "Um colchão forrado com tecido rústico", "uma cadeira antiga" e "uma mesinha de centro de Gonçalo-Alves" eram também mencionados. Parece relevante que a madeira seja nomeada: Gonçalo-Alves é uma árvore - Astronium fraxinifolium - originária do cerrado, vegetação do interior onde se forjara a origem da autenticidade brasileira por diversos autores do fim do século XIX a meados do XX.

Os termos rústico, antigo e primitivo compunham o léxico de apresentação da casa da artista. Os "quadros abstracionistas" de Krajcberg, Gamarra e diversos outros artistas transformavam o sentido dos termos citados em signo de distinção, identidade e ancestralidade em oposição aos possiveis sentidos de pobreza, destituição de cultura ou conhecimento implícitos na noção de primitivo, até então privilegiados. É dessa mistura de sentidos que se destacava a "originalidade" da artista em sua maneira de compor 0 ambiente e, em um passe de mágica, passava-se de sua forma particular de decoração para a generalização da ideia de "originalidade" na totalidade dos artistas: "a qualidade dos quartos e objetos de arte empregados na decoração dá o toque de originalidade, que geralmente caracteriza as residências de artistas plásticos".

Treze anos depois, a revista Casa e Decoração ${ }^{18}$ trazia a chamada de uma de suas principais colunas: "umas pitadas generosas de peças de artesanato típico brasileiro. Com essa receita do arquiteto Paulo Terra, é possível conseguir mais que uma decoração, um habitat". "Um habitat bem brasileiro". "Diz-me como moras que te direi que és" é como começa a coluna sobre a decoração de Paulo Terra. Na propaganda da página que encerra a reportagem, Óleo de Peroba era vendido com a chamada "A natureza viva em sua casa", "para conservar a beleza, a nobreza e proteger através dos anos". A ideia de uma natureza viva em sua casa remetia também ao mito fundador do Brasil tal qual descrito por Marilena Chauí (2001), o paraíso terrestre por oposição à civilização e à modernidade. Nesse contexto, entretanto, a natureza e a rusticidade eram parte constituinte dessa modernidade.

\section{Podem os objetos agir sobre as pessoas?}

A nação surgiu nas primeiras décadas do século XX, principalmente, a partir da constituição de um patrimônio histórico, geográfico e artístico, como dimensão integradora da sociedade nacional. Nesse processo, as criações culturais de povos autóctones como distintivas da brasilidade - assim como de diversas outras identidades nacionais $^{19}$ - foram na segunda metade do século incorporadas às representações de uma natureza nacional não somente através de valores, mas como matéria-prima para a confecção de objetos e também como objetos de consumo. A complexa relação entre natureza e cultura aparece no contexto do trabalho de Olly e da rede de relações da qual a artista participava como uma forma de constituir uma particularidade brasileira, aliando-a a outras produções culturais autóctones que despertavam intenso interesse das ciências: as culturas pré-colombianas e os povos indígenas brasileiros como objeto da antropologia, da arqueologia e da história.

0 material usado por esses povos para a produção de seus objetos de uso cerâmica, madeira, lã, algodão - era exaltado como parte de uma natureza cuja nobreza se construía em oposição à industrialização. Usar esses materiais para projetar móveis, interiores, roupas, joias era criar o novo a partir de valores que, ainda que levassem a indústria em consideração, se afastavam da indústria de massa. Surgia daí um processo dialético de construção entre os objetos, seus criadores e seus consumidores. Esses objetos, ao mesmo tempo que eram construtos 
de atores sociais, constituiam as subjetividades desses atores, vinculando-os a um pertencimento, paradoxalmente, regional e artístico.

Viver em uma casa com móveis "rústicos", com plantas "nativas" brasileiras e com objetos que remetessem ao mesmo tempo às ideias de modernidade, funcionalidade e simplicidade era construir-se como autêntico, moderno, criativo e brasileiro. Essa "brasilidade" foi, nesse período, uma construção em grande medida empreendida por estrangeiros de primeira ou segunda geração, como Olly, Joaquim Tenreiro, Norman Westwater, Rubem Gerchman, entre outros. A valorização dessa natureza, das cores que ela apresentava como referências à juventude, aos esportes e à comunicação estavam presentes também em músicas, roupas, na ênfase na praia - o Posto 9, as dunas do barato, no teatro e no cinema. A Bossa Nova e o Cinema Novo foram importantes agentes de produção desses sentidos e sua legitimação.

0 Ministério das Relações Exteriores patrocinou diversas exposições de Olly, no Brasil e em outros países. No entanto, não se pode falar em uma intenção sistemática de construção de símbolos de nacionalidade quando o campo artístico se constituía no Brasil, na Europa e nos EUA a partir da rejeição aos pertencimentos, principalmente nacionais ${ }^{20}$. Mas em um mercado artístico - artes visuais, música, cinema etc. - que se internacionalizava rapidamente, a particularidade nacional ainda era a melhor estratégia, especialmente para a obtenção de patrocínio governamental - tanto a Associação Internacional de Críticos de Arte (AICA) como a própria UNESCO, da qual a AICA era membro, organizavam-se em divisões nacionais.

Deve-se assim levar em conta a participação de diversos agentes e agências consagrados na transformação do trabalho de Olly em arte, a moda nos museus. Entravam nesse processo de produção da crença (BOURDIEU, 2004) não somente os objetos e as performances produzidos por ela, mas também os discursos elaborados sobre ela e sua produção com objetivos variados de projeção do trabalho no Brasil e no exterior e de obtenção de recursos. 0 período de sua atuação foi marcado por fenômenos independentes, de escalas bastante distintas, mas ao mesmo tempo interdependentes: a transformação interna dos valores da produção e do produtor artístico, o surgimento de novas instituições artísticas e a internacionalização desse campo através principalmente do surgimento da Bienal de São Paulo e da Associação Brasileira de Críticos de Arte, vinculada à seção internacional dessa Associação. Esses três fenômenos se interligavam na imprensa impressa vinculada, de diversas formas, a agentes relacionados, seja às instituições de arte, seja à crítica de arte.

Em 1961, um de seus trabalhos foi displicentemente colocado como ilustração de uma coluna que falava sobre o expressionismo alemão e sua expansão pelo mundo em virtude da Guerra ${ }^{21}$. É interessante o paradoxo de se apresentar no mercado artístico como brasileira e com uma produção relacionada à "natureza brasileira", mas ser constantemente apresentada como alemã radicada no Brasil. Olly, como alemã, contribuia ao mesmo tempo para retirar da condição de simples exotismo a arte brasileira fundada na "natureza" e elevar essa mesma natureza à condição de "cultura", "civilização", reforçando a ideia de indivíduo criador liberto de laços de pertencimento - nacional ou étnico ${ }^{22} .0$ tema do fenômeno artístico no Brasil das décadas de 1950 a 1970 não foi simples nem linear e precisa ser investigado a partir das diversas escalas em que se inscreve, levando em conta o paradoxo da universalidade autodeclarada e do regionalismo institucional.

Até que ponto podemos pensar que nossas identidades estão distribuidas entre os diversos objetos que nos circundam e nos constituem? A ideia é fascinante, mas para levar em conta essa possibilidade precisamos considerar em que contexto foram criados, a partir de que concepções e posicionamentos políticos. Atribuir agência ao mundo material não pode ser uma forma de retirar a intencionalidade e a responsabilidade das pessoas (MACDONALD, 2006). 
As roupas de Olly eram nesse contexto apresentadas como dimensões constitutivas de um tipo de personalidade - criativa, inteligente, sensivel, moderna, jovem (termos que aparecem espalhados nas colunas que tratam de suas criações) - remetendo às vezes ao pertencimento nacional, às vezes ao domínio da criação universal. Se tomarmos a ideia de pessoa distribuida (GELL, 1998), podemos pensar esses objetos de indumentária como portadores da dimensão objetiva dessa identidade, o mana, ou seja, a dimensão compartilhada (MAUSS, 2003) daquela personalidade. No entanto, a roupa não construía somente a identidade de Olly, mas também daquelas pessoas que as portavam. Ao adquirir uma roupa de Olly, portava-se consigo o mana da própria produtora no corpo.

É assim que a artista Maria Luíza Leão descreveu, em 1998, a sensação diferencial de usar uma roupa feita por Olly:

Essas duas roupas que ainda tenho eu comprei quando comecei a namorar meu marido. Na década de 1960. Eram roupas que eu me sentia diferente. Sabe aqueles vestidos que dão sorte? Aquele vestido que cada vez que você põe você se sente bem e que as coisas dão certo. A coisa é fantástica. 0 vestido pode ser usado de frente e de costas. Tem um lado que é laranja e um que é mais fechadinho. Então conforme meu mood, eu usava um ou outro. 0 outro acabou porque era de uma fazenda muito fininha. 0 outro era azul, muito bonito ${ }^{23}$.

Daniel Miller (2013) critica o julgamento da roupa - e aqui podemos ampliar a crítica a outros objetos de uso mais ou menos pessoal - como superficialidade por essa concepção ser devedora de uma "ontologia da profundidade". A partir dessa noção, construída em grande medida pelo romantismo alemão em oposição ao iluminismo francês, seríamos pessoas "interiorizadas", cujas personalidades se constroem nas profundezas de nosso ser. Assim, as roupas e tudo aquilo que fica literalmente à superficie seria considerado "mera" aparência e, portanto, descartável. Sua crítica se refere à confusão entre a metáfora da profundidade do ser e a literalidade da superficialidade das roupas. Para Miller (2013), as roupas não representam as pessoas, mas as constituem.

Se levarmos em conta que não existe um âmago, um cerne da pessoa a que se chega depois de retiradas as superficialidades, como as roupas e os acessórios, chegamos a um processo constante de construção de si na relação com os objetos, roupas e acessórios, mas também com todos os outros objetos com os quais optamos por nos rodear. Se observarmos os discursos sobre as roupas de Olly e também sobre decoração em relação aos diversos nomes aqui mencionados, assim como ao desenho gráfico, veremos que se trata menos da preocupação em seguir tendências ou estilos e mais da construção de uma estética baseada em como combinar roupas, acessórios, mobiliários etc., assim como uma preocupação com uma forma específica de estruturação do espaço doméstico. Como se relacionar com o espaço - em suas diversas acepções - parecia ser a tônica dessa transformação.

Classificar determinadas cores associando-as a fenômenos da natureza, considerados signos de brasilidade era também atribuir aos objetos construídos a partir desses discursos agência capaz de constituir subjetividades ao mesmo tempo modernas e joviais, tanto no sentido cronológico como no da capacidade de se adaptar às novas exigências ${ }^{24}$. A relação com a natureza, esse espaço físico e conceitual que nos engloba, se dava a partir dos materiais "naturais" - Olly só trabalhava com algodão em plena época da Rhodia e dos tecidos sintéticos -, mas também das cores. A mulher, categoria social mais próxima da noção de natureza, por oposição ao homem relacionado à cultura, era a principal consumidora desses produtos, mas também produto desse contexto de reformulação dos valores acerca da natureza. 
[Recebido em: 24/07/2015]

[Aprovado em: 21/09/2015]

\section{NOTAS}

${ }^{[1]}$ Este trabalho é resultado do projeto Olly e Werner Reinheimer: moda, arte e política. Do arquivo pessoal ao patrimônio nacional, financiado pelo edital Universal do CNPq, 2013, e pela Faperj, através da bolsa Jovem Cientista no Nosso Estado, 2015. 0 projeto vem organizando o acervo do casal Olly e Werner Reinheimer, que ficará disponível em formato eletrônico no endereço: <http://r1.ufrrj.br/olly/ index.php/>.

${ }^{[2]}$ Depoimento pessoal à autora em 1998

[3] As referências que aparecem nas figuras remetem às classificações da Coleção Olly e Werner Reinheimer e poderão ser encontradas online em futuro próximo.

${ }^{[4]}$ MROW-G 26, MROW-G 25 e MROW-G 07. As referências utilizadas nas notas de rodapé deste ensaio dizem respeito ao Arquivo Olly e Werner Reinheimer que vem sendo organizado e digitalizado e estará brevemente disponivel no endereço: <http://r1.ufrrj.br/olly/index.php/>.

${ }^{[5]}$ Documento MROW-G 31 do acervo Olly e Werner Reinheimer.

6] Por oposição à música "ao vivo", e não como um estilo.

[7] Documento MROW-G-38 do acervo Olly e Werner Reinheimer.

${ }^{[8]}$ Documento MROW-G-38 do acervo Olly e Werner Reinheimer.

${ }^{[9]}$ Documento MROW-G 35 do acervo Olly e Werner Reinheimer.

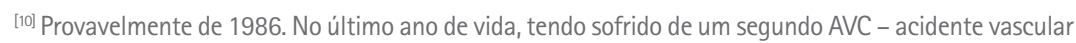
cerebral - e perdido os movimentos parciais de um lado do corpo, Olly dedicou-se a escrever sobre seus processos de trabalho, inventários de seus objetos e suas memórias.

${ }^{[11]}$ Documento MA-37 do acervo Olly e Werner Reinheimer.

${ }^{[12]}$ Documento MROW-G 39 do acervo Olly e Werner Reinheimer. Em depoimento à autora, em 2015, Duda disse ter usado o vestido no Festival de Cannes.

${ }^{[13]}$ Depoimento de Rene Reinheimer à autora em 1998.

${ }^{[14]}$ Tendo fugido da Alemanha por causa do nazismo, na década de 1930, e sendo casada com um ex-militante da resistência judaica alemã filiado ao Partido Comunista brasileiro, imagino que se apegar a uma identidade nacional brasileira possa ter sido também estratégia de sobrevivência.

[15] Joaquim Pedro de Andrade (filho de Rodrigo Melo Franco de Andrade, que lhe deu consultoria para a criação de alguns de seus filmes, entre eles, Macunaíma), Paulo Cesar Saraceni, Mario Carneiro, Cacá Diegues.

[16] Não confundir com a que foi editada pelo grupo de São Paulo, em meados de 1970.

${ }^{[17]}$ Documento MROW-G-80 do acervo Olly e Werner Reinheimer.

${ }^{[18]}$ Documento MROW-G-82 do acervo Olly e Werner Reinheimer.

${ }^{[19]}$ Ver Reinheimer (2007), onde faço uma discussão sobre a Identidade nacional como estratégia política.

${ }^{[20]}$ Ver Reinheimer, 2014.

${ }^{[21]}$ Documento MROW-G 02 do acervo Olly e Werner Reinheimer.

${ }^{[22]}$ Está implícita nesse processo também a ideia de assimilação que esteve presente no imaginário brasileiro durante toda a primeira metade do século XX no pensamento, por exemplo, de Silvio Romero.

${ }^{[23]}$ Depoimento à autora em 1998. A roupa que ela descreve é a apresentada na figura 2.

${ }^{[24]}$ Diversos entrevistados mencionam a jovialidade de Olly. Um exemplo é Sérgio Campos Mello: "Ela era 18 anos mais velha que eu, mas nossa diferença de idade não transparecia no dia a dia. Ela era de uma juventude incrivel. Não aparentava sua idade de jeito nenhum. Em uma conversa ela puxava alguma coisa de dentro da bolsa e começava a costurar ou a tecer. Ela estava sempre produzindo" (1998). 
artigo ] PATRÍCIA REINHEIMER

\section{REFERÊNCIAS}

ANDERSON, Benedict. Imagined Communities. Reflections on the Origin and Spread of Nacionalism. London-New York: Verso, 1983.

BECKER, H.S. Art Worlds. Los Angeles: University of California Press, 1982.

BOURDIEU, Pierre DELSAUT, Yvette. 0 costureiro e sua grife. Contribuição para uma teoria da magia. In: A produção da crença: contribuição para uma economia dos bens simbólicos. São Paulo: Zouk, 2004 [1975].

CASTRO, Ruy. Ela é carioca: uma enciclopédia de Ipanema. São Paulo: Companhia das Letras, 1999.

CHAUI, Marilena. Brasil: mito fundador e sociedade autoritária. São Paulo Editora Fundação Perseu Abramo, 2001.

GELL, Alfred. Art and Agency: an Anthropological Theory. Oxford: Oxford University Press, 1998. HEINICH, Nathalie. Le triple jeu de l'art contemporain. Paris: Les Éditions de Minuit, 1993.

HOBSBAWM, Eric. Era dos extremos: o breve século XX. 1914-1991. São Paulo: Companhia das Letras, 2005.

MACDONALD, Sharon. Words in Stone: Agency and Identity in Nazi Landscape. Journal of Material Culture, V. 11(1/2), p. 105-126, 2006

MAUSS, Marcel. Ensaio sobre a dádiva. In: Sociologia e antropologia. São Paulo : Cosac e Naify, 2003 [1922].

MAZIERO, Dalton Delfini. A arte pré-colombiana nas bienais de São Paulo:

um referencial para nossa identidade cultural (19512003). Disponivel em: <http://www.

arqueologiamericana.com.br/artigos/artigo_07.htm>. Acesso em: 27 fev. 2015.

MILLER, Daniel. Trecos, troços e coisas: estudos antropológicos sobre a cultura material. Rio de Janeiro: Zahar, 2013.

REINHEIMER, Patrícia. Identidade nacional como estratégia política. Mana, vol.13, n.1. Rio de Janeiro. Abril, 2007.

ZOLBERG, Vera. Incerteza estética como novo cânone: os obstáculos e as oportunidades para a teoria da arte. Dossiê artes e humanidades. Ciências Humanas e Sociais em Revista. Seropédica, vol. 31, janeiro junho, 2009 